\title{
International Collaboration as a Catalyst for Change: The Case of Nanyang Technological University, Singapore 2003-2017
}

\author{
Guaning Su
}

\section{Introduction}

\subsection{Genesis}

I had the honour of serving as the second president of Nanyang Technological University (NTU) from 1 January 2003 to 30 June 2011. Following the end of my term, Professor Bertil Andersson, whom I had recruited in 2007 as the first Provost, continued our work as my successor. By the end of Andersson's term on 31 December 2017, we had engineered, together with Emeritus Professor Haresh Shah of Stanford University, an unprecedented transformation of a large university in a relatively short time of fifteen years. This transformation and a detailed account of how we did it are discussed in our new book under preparation [1].

I was a university president in a hurry from the first day of my presidency on the 1st of January, 2003. I began introducing initial reforms while carrying out the government decision to expand the university undergraduate enrolment by 6300 students. This was to be done by building three new schools in Humanities and Social Sciences, Art, Design and Media and Physical and Mathematical Sciences as part of the Singapore plan to expand the university sector. The granting of university autonomy as well as the establishment of the National Research Foundation of Singapore in 2006 provided the empowerment and the resources for a thorough revamp of the leadership and the faculty to meet the new research-intensive innovation requirements. From the beginning of my term on the 1st of January, 2003, until the end of Andersson's term on the 31st of December, 2017, the university experienced a quantum leap in international stature as a result of dramatic increases in research output and research quality. While rankings are incomplete measurements of universities, the magnitude of NTU's

G. $\mathrm{Su}(\bowtie)$

Nanyang Technological University, Singapore, Singapore

e-mail: guaning@ntu.edu.sg transformation can be seen from the 2020 QuacquarelliSymonds (QS) World University Rankings [2] in which NTU now ranks joint 11th in the world.

In this chapter, I shall examine the role of globalisation in the transformation of NTU and argue that international resources can only serve as the catalyst. Sustainable transformation is not possible without meaningful and often painful internal reform. Because of this caveat, transformations such as we achieved in 15 years are still rare events in the chronicles of higher education.

\subsection{Historical Background}

NTU was founded as a practice-oriented engineering college named Nanyang Technological Institute (NTI) in 1981. It received its university charter by an Act of the Singapore Parliament [3] in 1991. Singapore has always looked upon the university as an instrument for economic growth. As a result, the Economic Development Board (EDB) has a major influence on manpower planning and higher education policy. As Singapore's economy continued to develop rapidly and the demand for engineers skyrocketed, NTI was created to answer this need. Between 1991 and 2002, NTU developed as a professionally focused university graduating engineers, executives, accountants and media professionals.

By 1999, Singapore's economic strategy had shifted towards research, innovation and entrepreneurship [4]. By 2003, when I took office, change was overdue. At a per capita GDP of roughly USD 50,000, Singapore faced an uphill task to ensure that our innovation and productivity gains kept pace with GDP growth.

As President NTU, I began engineering a major transformation of the university. International networks and collaboration played an important part. However, we cannot simply rely on an external party to strengthen our capabilities. Otherwise, the impact is gone as soon as the external party disengages. The impact of international collaboration 
was catalytic in that it provided the role model and advice. We still had to figure out how to overcome the natural human resistance and create a sustainable model of excellence. Here, the government, as the ultimate sponsor and customer of the university's output, played a crucial role. Fundamental internal reforms were necessary if the drive of the university was to create the necessary impact. This internal reform is the hardest part of a university's transformation and a focus of our forthcoming book [1].

\subsection{Competitive Position}

In 2002, before I took office, NTU was a regionally known and professionally focused teaching institution. My predecessor, Professor Cham Tao Soon, had written extensively on the 1981-2002 period in the NTU Story [5] and NTU Story Part II [6]. NTU was used to occupying the number 2 position in a comfortable duopoly with the National University of Singapore (NUS), but in 2003, it was in danger of dropping to number 3 in student preference. This risk arose with the entry of a smaller, livelier and Ivy League linked rival, Singapore Management University (SMU). SMU was set up in collaboration with the Wharton School at the University of Pennsylvania. There was a real danger of NTU ending up as number 3 , scraping the bottom of the barrel in student intake quality. I had to take urgent action. Very quickly in February 2003, we announced NTU's move towards a flexible curriculum with many more choices of majors, minors and combinations thereof, which we branded as the New Undergraduate Experience. This event heralded the beginning of NTU's historic transformation. Teaching led the way.

At the time, NTU research was industry cooperation oriented. Top-level research was patchy. NTU had very little mindshare in top-level international research. I realised that simultaneous changes had to be made throughout the university. Eventually, it took not just one, but three high-powered individuals to achieve the ambitious goals I had in mind back in 2003. The outcome in 2018 was way beyond the expectations of the three of us.

\subsection{Building the Team}

As I was parachuted into the NTU presidency, it took me some time to get to know the people and more time to adjust the structure and develop a core team of like-minded leaders to drive the transformation. From 2003 to 2005, I tapped the existing university leadership to help out in the transformation. The result was mixed. Not all of them saw the need to change. Some did see the entry of the third university as a threat but were at a loss on what could be done. No one worried about the economy passing us by and the need for research and innovation that we are duty-bound to provide but were unable to at the time.

The reforms stalled as we were bogged down with regular administrative issues. There were insufficient continuity and enforcement to push reforms on all fronts simultaneously. On the positive side, our drive to establish three new schools was making good progress, and all three were in operation by 2005 .

\section{Seizing the Opportunity}

\subsection{QAFU Review, Autonomous Universities and National Research Foundation}

Fortunately, the opportunity for major reform came soon after this. The 2005 Quality Assurance Framework for Universities (QAFU) Review [7] endorsed our direction but was politely critical of the ad hoc nature of change. This supported the case I had been putting forward to move towards a provost structure, making the appraisal process inherited from the days as a government agency much more academic and transparent.

\subsection{University Autonomy}

The 2005 meeting of the Singapore Ministry of Education's International Academic Advisory Panel (IAAP) endorsed the Singapore Ministry of Education's proposal [8] to grant NUS and NTU autonomy, with a performance requirement and outcome-based funding, freeing our hands in fund-raising. I gratefully accepted the suggestion to recruit a provost with the utmost urgency and to build the university governance tapping well-established examples such as Stanford. The suggestion may have come from Gerhard Casper, President Emeritus of Stanford University, a member of the QAFU assessment panel.

\subsection{National Research Foundation}

Just as important as gaining autonomy and recruiting a provost was the establishment of the National Research Foundation (NRF) to provide strategic research funding within Singapore. In one stroke, the universities were freed to make proposals for grants from the NRF with single programme funding up to $150 \mathrm{M}$ Singapore dollars, a mind-boggling sum at the time. This sum in turn gave the universities firepower to recruit the very best from around the world. 


\section{The Nanyang Troika}

The recruitment of Bertil Andersson as Provost gave me a partner with vision who could be trusted to push our agenda with all his might. Haresh Shah was chair of the search committee. When Andersson signed his contract, our core team was complete. The third member of this Troika, Professor Haresh Shah, was a former department chair, entrepreneur and professor emeritus at Stanford. He was familiar with the system at Stanford and was keen to change NTU. He became a member of the Board of Trustees and chairman of the board-level Academic Affairs Committee. The Troika met for the first time in Aptos, California and brainstormed ten significant projects. After fifteen years of hard work, when Andersson stepped down in 2017, most of the targets had been achieved and validated externally. What happened between 2003 and 2017 was nothing short of miraculous.

By 2017, NTU Singapore was a highly regarded research-intensive university with a global reputation. We achieved our highest ever ranking at number 11 in the QS World University Rankings in 2017 and 2020. We were also the highest ranked Asian university in normalised research impact.

\section{The Nature of Globalisation}

As an important window to the world and a wellspring of ideas, not to mention the cradle of leaders, movers and shakers, the modern university cannot help but globalise. The nature and extent of globalisation differ between institutions because the mission of the university varies and evolves with time.

As already mentioned, NTU came into being as Nanyang Technological Institute (NTI) in 1981 on a campus bequeathed by its predecessor Nanyang University, a Chinese language university serving the Chinese community in South East Asia ("Nanyang" to the Chinese). NTI's founding mission in 1981 was to train large numbers of practice-oriented engineers for the Singaporean economy. Being chartered as NTU, a full-fledged university, in 1991, did not change the mission but broadened it to include educating professionals in accounting and business as well as mass communications. It was appropriate, with this mission, that globalisation had a practice rather than research focus. Some senior leaders even actively discouraged young colleagues from doing research on the premise that it was irrelevant to the university.

\section{International Collaboration with Top Schools}

\subsection{The MIT Review}

As the Singapore economy began to mature and achieve a high GDP per capita, this vacuum in research became a shortcoming. In 1997, the International Academic Advisory Panel was set up by the Singapore Ministry of Education. In 1998, the Ministry commissioned a team of professors from MIT to review NTU and sister institution National University of Singapore (NUS). The team recommended a change from the British style of narrow, but deep education towards a broad undergraduate curriculum and a renewed emphasis on research [9].

\subsection{Singapore-MIT Alliance}

A deal was struck with MIT to begin a major research collaboration between MIT, NUS and NTU. It was dubbed the Singapore-MIT Alliance (SMA). This was a clear signal from the government that world-class research was demanded for both NUS and NTU. SMA was a classic case of financial considerations being used to help establish somewhat unequal research collaboration. Of course, the disparity in capabilities cannot be too great or else meaningful collaboration would not be viable.

Looking back, the SMA programme was positioned well. SMA did not only raise the level of research in both NUS and NTU but also provided much needed affirmation that some of our faculty can match the best in the world. This confidence was an important prerequisite for the subsequent transformation of both universities.

\subsection{SMART}

It is important to keep in mind that globalisation is a many-to-many courtship dance. Contacts and mutual visits are used to size each other up. The relationship is normally polygamous. Deals are consummated all the time, just as some deals outlive their welcome and lapse. SMA served its purpose well. It's follow-up, SMART, where RT stands for research and technology was a collaboration on a more equal basis. Today, NUS and NTU, the two flagship universities in Singapore no longer require "foreign aid" programmes, but instead attract collaboration from peer institutions on an 
equal basis. In addition, both universities have now become attractive targets being wooed by others to help them raise their levels of research.

\section{International Networks}

Every university worth its salt is a node in a number of international networks of universities. This is a sweeping statement, but nonetheless true. Consider, first of all, the essential component of any university: the teaching faculty. Except for a very small number of bespoke institutions such as military academies, it is necessary to cast the recruitment net far and wide; in other words, a world-wide search is often best. This is globalisation on the fundamental professorial level.

What about the recruitment of students? A university typically has a student body drawn from many countries around the world. While those from the home country are always the dominant component, students in most countries around the world aspire to attend the best global universities wherever they are physically located. Whether their dream schools are in their home country is immaterial. Increasing affluence also allows them to broaden the scope of their search for the ideal university by going international.

\subsection{Research Collaboration}

The most globalised university activity is research. The broad themes of research tend to follow a global consensus and do not vary much country to country. There is considerable agreement among all countries on which are the most important problems facing mankind. It is also the nature of research that progress is incremental and often multinational. The more advanced university's research, the more important their international network is, often built by professors for particular big problems or grand challenges.

The topology of a university's international network is multidimensional. At the most fundamental level, it is a person-to-person relationship usually based on a shared research interest. Unsaid, but very important, is that the relationship must create a win-win situation. If the levels of research are too disparate, one side feels exploited and taken advantage of while the other side feels inferior and worse, looked down upon. Neither case leads to a sustainable relationship.

At the university-to-university level, relationships are an aggregate of individual relationships augmented by institutional links, typically in alliances and collaboration in joint teaching and research. At this level, the matching of capabilities is even more important. If there is a major gap in capabilities, even though collaboration can still be sustained for some time with the lubrication of funds offered in compensation to the stronger partner, eventually, the weaker partner drops out because the gains do not justify the cost.

\subsection{NTU Networks}

NTU, too, had these multidimensional networks back in 2003 when I began to push its transformation. The networks were built up mainly for the 1981 mission of educating practice-oriented engineers and for foreign policy needs, such as those pertaining to the Association of Southeast Asian Nations (ASEAN). However, by 2003, these networks had become less relevant to serve the needs of a high income (and therefore high cost), innovation-based and high value-added economy where technological innovation is key to obtaining the necessary value added. For example, the Commonwealth Engineering Council (CEC), with participation from all former British colonies, was useful at the beginning of NTI to provide references on curriculum and linkages to multinational corporations. NTI even received accolades from the CEC for having developed one of the best engineering programmes in the world.

In 2003 when I assumed office, these links with largely teaching universities and industry employers of our graduates were dominant, taking up both resources and attention from management. I set out to develop international links that would be helpful for the progress of NTU in the context of the new demands of the nation, mainly on high-level research. Today, NTU's set of partners mostly come from the top tier of research universities.

\subsection{Tapping Top Schools}

Having worked with MIT in the SMA Programme since the late 1990s, MIT was a natural target. As I had a degree from Caltech and the Caltech presidential couple David Baltimore and Alice Huang were frequent visitors to Singapore by virtue of their engagement with the Agency for Science, Technology and Research (A*Star), the national research institute, these two top-rated technological powerhouses were attractive to engage. Of the two, I had more success with Caltech, partly because of alumni links, but also because MIT was quite content to let the relationship evolve naturally without too much pushing. Another success was our engagement with Stanford, the Silicon Valley powerhouse. It is interesting to see how these engagements with three of the very best tech schools turned out.

\subsubsection{MIT}

With MIT, besides the SMA programme, we had developed collaboration between our Nanyang Business School and 
Sloan School of Management at MIT. This was the Nanyang Fellows programme, aiming to create a small and intimate environment for talented officials from the ASEAN region in an MBA-like programme. The aim was political-to develop early friendship among officials in ASEAN countries. Both the SMA programme and the Nanyang Fellows programme involved financial benefits for MIT. We were happy to pay the premium as both programmes benefitted the reputation and quality of two of our biggest schools, engineering and business. I visited MIT within a few months of taking office, but the meetings were more courtesy calls and reviews. MIT Provost Robert Brown was a long-serving member and Chairman of the IAAP where we can get in touch with him easily.

The next major move by MIT was the Singapore MIT Alliance on Research and Technology Programme within the Campus for Research and Technological Entrepreneurship (CREATE), where foreign universities of high standing were invited to set up research laboratories in Singapore. Of all the foreign universities in CREATE, MIT probably had the best deal with five programmes funded. NTU was not very involved. Overall, I would say NTU benefitted from MIT due to the good decisions from the incisive leadership of Robert A. Brown as Chairman of IAAP as well as because of the branding effect of participating in MIT led programmes.

\subsubsection{Stanford}

In 2003, I signed the Singapore-Stanford Partnership Agreement with President John Hennessy of Stanford. Background work on this agreement to collaborate on environmental engineering research and conduct master's and doctoral programmes was done by my predecessor. It was a typical agreement with a university with a higher overall research achievement and reputation. Stanford had the number 1 ranked environmental engineering programme. Environmental engineering was a specialised area of concentration in NTU and an area of emphasis in Singapore's research strategy. Thus, it was natural to offer financial inducements as sweeteners for collaboration. We must be aware, however, that the capability gap cannot be too large. No university want to have their top faculty bogged down bringing up someone else's faculty. It was a credit to NTU's environmental engineering faculty that Stanford saw it worth their while to collaborate, financial inducement or not.

During the course of my presidency, there were other occasions when we sought out Stanford as a partner. But the Stanford philosophy of tight control of their faculty quality meant that no other programme materialised. We did, however, through Haresh Shah, benefit from the Stanford experience as our governance framework concerning the Academic Council, the Senate, Senate Committees and the Advisory Committee were largely adapted from the ready-made systems at Stanford.

\subsubsection{Caltech}

NTU's relationship with Caltech was interesting and much deeper than the links with MIT or Stanford. Among my alma maters, I spent the least amount of time in Caltech as my $\mathrm{Ph}$. D. programme was cut short by the Singapore government's insistence that I return to Singapore after completing my M. S. which I had finished in three quarters. I am most grateful to Caltech though, not only because I had a fellowship with no strings attached, but because a Caltech GPA of 4.0 opened many doors when I did resume applying for doctoral admissions.

Caltech also had a close relationship with the Singapore national research institutes, its president, Nobel laureate David Baltimore having struck up a relationship with the Chairman of A*Star, Philip Yeo, upon the launch of Singapore's ambitious biomedical initiative in 2000. David and his wife Alice Huang, a formidable scientist in her own right, were frequent visitors to Singapore. We were to become good friends. Philip Yeo invited Caltech to send a team to review NUS and NTU with a view towards establishing a new pharmaceutical chemistry programme. David Tirrell, then Head of the Chemistry and Chemical Engineering Division at Caltech, now provost, led the team.

At the time of the Caltech visit, NTU was just beginning to assemble the leadership for the new School of Physical and Mathematical Sciences while NUS had a strong and long-established chemistry department. The Caltech team recommended that $\mathrm{A} *$ Star establish the new chemistry programme in NTU where a fresh start was possible without any baggage from the past. I took a personal interest in the project as a Caltech alumnus, with the help of Freddy Boey, Chair of the School of Material Science and Engineering, and later Lee Soo Ying whom I recruited while he was on sabbatical at Berkeley after having stepped down from his Vice Provost position at NUS. Appointed Dean of Physical and Mathematical Sciences, he was a tremendous help to me in recruiting outstanding young faculty. Some of the recruits were from NUS which earned us howls of protest from their president.

What $\mathrm{A}^{*}$ Star wanted was a strong pharmaceutical chemistry programme. Consistent with David Tirrell's findings, we set out to recruit young and promising faculty. To ensure good quality control, we proposed to recruit the young faculty jointly with Caltech and have them spend two years teaching and conducting research there before coming back to NTU. Obviously to make it worth their while, there were financial sweeteners for Caltech.

When we finally submitted what we thought was a winning proposal to $\mathrm{A} *$ Star, word came back that it was too expensive on a cost per Ph.D. graduated basis. But of course, this approach of building up faculty at the same time as students cost more. However, in the long run, it is more effective as we are building up our faculty at the same time as producing Ph.D.'s. Having world-class faculty is 
immeasurably more effective than sending groups of $\mathrm{Ph} . \mathrm{D}$. students to top schools.

What $\mathrm{A} *$ Star failed to take into account was the more important capability build-up in NTU research that would be a continuing source of high-quality Ph.D. graduates specific to industry requirements. Nevertheless, chemistry turned out to be one of our bright spots as we rose in stature and international reputation. Our relationship with Caltech helped significantly in the international exposure of our early recruits in 2004 which contributed to the prominence of NTU chemistry today.

\subsection{Competing for Research Centres of Excellence (RCE)}

Research Centres of Excellence were the flagship programmes of the NRF, each centre funded at SGD $150 \mathrm{M}$ or about USD $120 \mathrm{M}$. There were to be five centres budgeted. Each centre would be affiliated with a university and spend their budget over 5-10 years. As NTU did not have a tradition of high-level research, we lacked the international network from which we could try to recruit top scientists to lead the programmes. Most people did not think NTU stood a chance competing with NUS and expected all five centres to be won by NUS.

We were in a precarious position. It was impossible to pull ourselves up by our bootstraps. Even with an external inject, Professor Tony Woo, Vice President (Research) recruited from the University of Washington, Seattle, the quality of NTU proposals that floated to the top were of insufficient quality.

We achieved a final tally of 3 for NUS, 2 for NTU. The two NTU wins were the Earth Observatory of Singapore (EOS) and the Singapore Centre for Environmental Life Sciences Engineering (SCELSE).

\subsubsection{Earth Observatory of Singapore}

An even more important effect of our relationship with Caltech led to NTU winning two major research competitions. The first one led to the establishment of the Earth Observatory of Singapore (EOS) at NTU. We were able, for the first time, to recruit a prominent Caltech professor, Kerry Sieh, to NTU, who helped us write the winning proposal. What stood out also was the willingness of Kerry to give up his Caltech position with life tenure and come to NTU full time which really means tenure to the age of 65 . In light of the life tenure system in the USA, this was a tremendous sacrifice.

With Kerry at NTU, we had established in one stroke a world-class observatory of the natural and man-induced disasters in the South East Asia ring of fire, conducting research on earthquakes, tsunamis, volcanos and climate change due to global warming. Not only did this fill a vacuum in one of the hot spots of the world, but the close cooperation with local authorities in Singapore's neighbours also earned us considerable goodwill. For NTU, the award of the USD $120 \mathrm{M}$ grant was a tremendous affirmation and morale booster. The significance of the EOS award goes beyond this. It demonstrated that NTU could hold its own in competition with NUS for these mega-grants and that we had the necessary creativity to chart our own path rather than compete where others had a head start. An immovable barrier had been breached, so to speak.

By this time, Jean-Lou Chameau had taken over from David Baltimore as President of Caltech. I knew Jean-Lou from his outstanding work at Georgia Tech where he was Dean of Engineering and later Provost, one of the triumvirate leadership at Georgia Tech responsible for their rapid rise in recent years. So, it was in friendly discussion with Jean-Lou that we applied the finishing touches to Kerry's move to NTU, including the price we paid for Kerry's tectonics movement instrumentation in Sumatra.

\subsubsection{Singapore Centre for Environmental Life Sciences Engineering}

There was one final touch by Caltech on NTU's research excellence. Jean-Lou Chameau had been invited as Caltech president to be a member of Singapore's IAAP. Next to the indefatigable Robert Brown, the President of Boston University, he was probably the most eloquent advocate of well-constructed and articulated research proposals. Our research proposal for the final round of the NRF's Research Centres of Excellence grant calls had everything. We proposed to establish the Singapore Centre for Environmental Life Sciences Engineering (SCELSE). Tapping the tremendous progress in genetic sequencing and inspired by gene-sequencing pioneer Craig Venter's voyage around the world to collect the genetic makeup of oceans, we proposed investing in the sequencing of microbial communities and developing engineering techniques to put them to use or to influence their behaviour. Not only would this effort create a new engineering discipline, it held out tremendous promise for environmental remediation and bodily infection intervention. Moreover, our Principal Investigators comprised not just NTU faculty and world-renowned authorities coming to NTU but also faculty in NUS, our local competitor. Rumour has it that this was the only proposal ever passed unanimously. Robert Brown and Jean-Lou Chameau's influence no doubt loomed large in such a deliberation. This move set up a collaboration model between the two Singaporean universities, often bitter rivals, creating a positive atmosphere of working for the national good. 


\subsection{National Research Foundation, Autonomous Universities and New Talent}

Singapore's National Research Foundation made big resources available for competition by the major players, namely NUS, NTU and $\mathrm{A} *$ Star, the national research organisation. As autonomous universities, NUS and NTU became not-for-profit corporations, freed from the constraints of government processes and procedures. One particular outcome was the welcome ability to tailor compensation packages for exceptional academic talent. Coupled with the opportunity to win big research grants up to $120 \mathrm{M}$ USD, this allowed both NUS and NTU to bring in exceptional senior faculty. Once the compensation barrier was breached, the horizon opened up suddenly for recruiting top talent at all levels including Assistant Professors.

In NTU, we created the Nanyang Assistant Professor (NAP) scheme in 2007 to bring in exceptional young talents through contact with the top laboratories around the world. Subsequent to NTU establishing the NAP scheme, the National Research Foundation set up the NRF Fellows scheme aimed at recruiting some of the best young principal investigators (PI) from around the world to Singapore. NTU worked hard to attract a fair share of the Fellows to NTU. The selection of the Fellows was entrusted to an international panel of prominent authorities in various areas of research and industry. I was the only Singaporean among them. We kept the work of the selection panel very low key to minimise lobbying problems.

NTU has had numerous collaboration programmes with international universities. These have tended to be specific programmes such as SMA with MIT, the Singapore-Stanford Partnership for environmental engineering and water treatment, Harvard Business School for our Asian Case Centre, and Carnegie Mellon for our M.Sc. in Financial Engineering. In each of these programmes, we learned something from the more advanced partner. We in turn are courted by many universities to collaborate with them, often with the backing of political relationships. Of all the foreign country relationships, the most important and most interesting is China.

\subsection{China Programmes}

Way back in 2003, when China's global influence was still small although growing rapidly, I had already determined that the engagement of China, tapping our Chinese speaking Nanyang University heritage, was a useful competitive strategy. We already had a head start with our so-called Mayor Class. This programme started in 1992 when paramount Chinese leader Deng Xiaoping suggested learning from Singapore. This was a one-year full-time Master programme taught in Chinese, aimed at educating Chinese senior officials in "Managerial Economics". This prepared them to manage market economies as required when China opened up with its reforms. It was dubbed the Mayor Class by the media as many of the officials became mayors of cities and beyond upon return to China. Building on the success of this programme, by the end of my term, we counted seven China-related master's programmes.

Besides the original Mayor Class, we added a more general Master of Public Administration, referring to both as Mayor Classes. The business school added an Executive Master of Business Administration, and the National Institute of Education added a Master's in Educational Administration. It was dubbed the Principal's Class. The Nanyang Technopreneurship Centre added a Master in Technopreneurship and Innovation. The Business School added a Master of Finance. Later, when the Central Organisation Department of the Chinese Communist Party issued an edict prohibiting party cadres from obtaining a foreign degree on government time and expense, our focus shifted to short-term courses and younger candidates and officials under different jurisdiction such as those from uniformed services and corporations.

As a result of these efforts, NTU has today over 20,000 senior-level alumni in China spread over all 35 provincial-level entities. A degree-conferring convocation ceremony has been held in China with all the pomp and circumstance of the home campus every year, at which the evening is devoted to building alumni relations and networks.

The impact of this important alumni network is yet to be fully felt, but with China jostling with the USA for world leadership, it will have an important, although as yet undetermined, impact on NTU, Singapore and the South East Asian region. The positive influence of NTU's China programmes on Singapore-China relationships has been, however, quite clear.

\section{Conclusion}

In this chapter, I have used the NTU example to illustrate how the Troika, itself a result of international relationships, was able to tap international collaboration to make possible the quantum leap at NTU. At first glance, one may attribute this to our globalisation efforts.

The benefits of globalisation are twofold. First, it provides good reference points to illustrate what is possible, and then it demonstrates the kind of actions necessary to do better. The reforms must initiate the right kind of behaviour; while at the right time, the system must lock in the desired changes.

Ultimately, the reforms at NTU were successful because we seized the opportunity and put in place mechanisms to 
keep and sustain the gains. For this, we attribute the achievement to the Troika, subject of a coming book on the rise of NTU being written by the three of us.

\subsection{The Role of Globalisation in the Transformation of NTU}

I had a wide-ranging globalised exposure in my education and work experience prior to coming to NTU. My undergraduate and postgraduate studies stretched over three countries-Singapore, Canada and the USA. My Alma Mater comprises five universities: the University of Alberta, Caltech, Singapore, Stanford and Harvard. My work experience in defence research also helped build me up to an international level that led to collaboration with Sweden, France, Australia, the UK and the USA. As serendipity would have it, while the search for the second NTU President was taking place, I was at Stanford studying the Silicon Valley entrepreneurship ecosystem. Not only did I get to know Haresh Shah there, but my links with Stanford and the Silicon Valley turned out to be very useful in the globalisation journey of NTU.

NTU's strong international relationships were further enhanced when we led the way in the formation of the Global Alliance of Technological Universities (GlobalTech), inaugurated in 2009 with seven universities across three continents. The alliance was formed on the basis of a common pursuit by these seven technological universities to improve the human condition and bring benefits to mankind, employing the technologies available. The founding members were Imperial College London, ETH Zurich, Caltech, Georgia Tech, IIT Bombay, Shanghai Jiao Tong, and NTU. The alliance is useful for branding ourselves with these top institutions.
From a position in the wilderness, Nanyang Technological University (NTU) has risen rapidly. The university is ranked joint 11th in the 2020 QS World University Rankings. Although international collaboration played an important part in this transformation, its influence is in surprising and non-traditional areas. It is easy to overestimate the importance of globalisation as it is a convenient scapegoat to blame for failure. The fundamental reason for NTU's rise is entirely internal.

\section{References}

1. Su, G., Andersson, B., \& Shah, H. (in preparation). The Nanyang Troika. World Scientific: Singapore.

2. Quacquerelli-Symonds World University Rankings, 2020. https:// www.topuniversities.com/university-rankings/world-universityrankings/2020. Accessed July 28, 2019.

3. Nanyang Technological University Act, Cap. 192, Singapore Statutes 1991, revised 9th March, 1992.

4. $\mathrm{Ng}$, E. H., et al. (2003). Restructuring the university sector-More opportunities, better quality. Report of the Committee to Review the University Sector and Graduate Manpower Planning. Singapore: Ministry of Education.

5. Lu-Sinclair, Y. T. (1995). NTU book. In The NTU story-The making of a university of industry and business. Singapore: Nanyang Technological University.

6. Leong, C., et al. (2002). NTU book. In The NTU story, Part IIComing of age. Singapore: Nanyang Technological University.

7. External Review Panel, Quality Assurance Framework for Universities, Validation Report on Nanyang Technological University, 2005.

8. Lim, C. P., et al. (2005). Autonomous universities, towards peaks of excellence. Report of the Steering Committee to Review University Autonomy, Governance and Funding, 4th April 2005.

9. Massachusetts Institute of Technology Internal Report, Strategic review of National University of Singapore and Nanyang Technological University engineering curriculum, 16th June, 1998.

\footnotetext{
Open Access This chapter is licensed under the terms of the Creative Commons Attribution 4.0 International License (http:// creativecommons.org/licenses/by/4.0/), which permits use, sharing, adaptation, distribution and reproduction in any medium or format, as long as you give appropriate credit to the original author(s) and the source, provide a link to the Creative Commons license and indicate if changes were made.
}

The images or other third party material in this chapter are included in the chapter's Creative Commons license, unless indicated otherwise in a credit line to the material. If material is not included in the chapter's Creative Commons license and your intended use is not permitted by statutory regulation or exceeds the permitted use, you will need to obtain permission directly from the copyright holder. 